\title{
Results from a proactive follow-up intervention to improve linkage and retention among people living with HIV in Uganda: a pre-/post- study
}

Caroline E. Boeke ${ }^{1 *}$ (D, Vennie Nabitaka ${ }^{2}$, Andrea Rowan ${ }^{2}$, Katherine Guerra ${ }^{1}$, Pamela Nawaggi ${ }^{2}$, Vivienne Mulema², Victor Bigira ${ }^{2}$, Eleanor Magongo ${ }^{3}$, Patricia Mucheri ${ }^{2}$, Andrew Musoke $^{2}$ and Cordelia Katureebe ${ }^{3}$

\begin{abstract}
Background: Despite gains in HIV testing and treatment access in sub-Saharan Africa, patient attrition from care remains a problem. Evidence is needed of real-world implementation of low-cost, scalable, and sustainable solutions to reduce attrition. We hypothesized that more proactive patient follow-up and enhanced counseling by health facilities would improve patient linkage and retention.

Methods: At 20 health facilities in Central Uganda, we implemented a quality of care improvement intervention package that included training lay health workers in best practices for patient follow-up and counseling, including improved appointment recordkeeping, phone calls and home visits to lost patients, and enhanced adherence counseling strategies; and strengthening oversight of these processes. We compared patient linkage to and retention in HIV care in the 9 months before implementation of the intervention to the 9 months after implementation. Data were obtained from facility-based registers and files and analysed using multivariable logistic regression.

Results: Among 1900 patients testing HIV-positive during the study period, there was not a statistically significant increase in linkage to care after implementing the intervention (52.9\% versus 54.9\%, $p=0.63$ ). However, among 1356 patients initiating antiretroviral therapy during the follow-up period, there were statistically significant increases in patient adherence to appointment schedules (44.5\% versus $55.2 \%, p=0.01)$ after the intervention. There was a small increase in Ministry of Health-defined retention in care $(71.7 \%$ versus $75.7 \%, p=0.12)$; when data from the period of intervention ramp-up was dropped, this increase became statistically significant $(71.7 \%$ versus $77.6 \%, p=0.01)$. The increase in retention was more dramatic for patients under age 19 years $(N=84 ; 64.0 \%$ versus $83.9 \%, p=0.01)$. The cost per additional patient retained in care was $\$ 47$.

Conclusions: Improving patient tracking and counseling practices was relatively low cost and enhanced patient retention in care, particularly for pediatric and adolescent patients. This approach should be considered for scale-up in Uganda and elsewhere. However, no impact was seen in improved patient linkage to care with this proactive followup intervention.
\end{abstract}

Trial registration: Pan African Clinical Trial Registry \#PACTR201611001756166. Registered August 31, 2016.

Keywords: Linkage to care, Retention in care, Follow-up, Quality of care, Uganda, Africa

\footnotetext{
* Correspondence: cboeke@clintonhealthaccess.org

${ }^{1}$ Clinton Health Access Initiative (CHAl), 383 Dorchester Road, Suite 400,

Boston, MA 02127, USA

Full list of author information is available at the end of the article
}

(c) The Author(s). 2018 Open Access This article is distributed under the terms of the Creative Commons Attribution 4.0 International License (http://creativecommons.org/licenses/by/4.0/), which permits unrestricted use, distribution, and reproduction in any medium, provided you give appropriate credit to the original author(s) and the source, provide a link to the Creative Commons license, and indicate if changes were made. The Creative Commons Public Domain Dedication waiver (http://creativecommons.org/publicdomain/zero/1.0/) applies to the data made available in this article, unless otherwise stated. 


\section{Background}

Ensuring that people living with HIV (PLWHIV) are enrolled in care and remain on treatment will be essential to reducing the global burden of HIV. However, in Uganda and elsewhere in sub-Saharan Africa, patient attrition in the testing and treatment cascade remains a persistent challenge [1-5]. A number of patient-level factors such as younger age, lower socioeconomic status, residence in rural areas, poorer health at diagnosis/treatment initiation, and experience of stigma have been found to be related to greater patient attrition in previous studies [6-11]. However, facility-level practices may play a role as well. Recent systematic reviews have identified several types of facility-level interventions that have been shown in certain settings to increase patient linkage and reduce patient attrition such as point-of-care testing [12-14], integrated services $[12,15]$, task-shifting care to laypeople or lower cadre health workers [14-17], service improvements/enhanced clinic operations [12], family-centered services [15], better counseling and education to provide adherence support [16], SMS messaging to support patient adherence to treatment [16], and differentiated care among stable patients $[17,18]$. Despite the success of these interventions in particular settings, more examples are needed of successful real-world implementation of low-cost, scalable solutions in national HIV programs. Moreover, despite greater attrition in children and adolescents compared to adults $[19,20]$, there is currently very limited data available on effective interventions to improve linkage and retention in adolescent patients [17].

In this study, we implemented a strengthened management intervention for proactive patient follow-up and enhanced counseling at 20 government-supported facilities in Central Uganda with high attrition from HIV care. We set out to evaluate linkage to care among individuals testing positive for HIV and six-month retention in care in antiretrovial therapy (ART) patients before versus after rollout of the intervention. At baseline, we noted that linkage to care was quite low (approximately $50 \%$ ) and that adolescents, females, and patients in more rural settings had lower linkage and retention [21]. This study provides a comprehensive assessment of a holistic but relatively low-cost intervention to improve outcomes in PLWHIV across age groups.

\section{Methods}

\section{Study setting}

This study was implemented in 20 randomly selected facilities across 14 districts in Central Uganda meeting the following criteria: Offered ART to pediatric and adult patients starting January 1, 2015 or earlier, low estimated annual retention among patients on ART (approximately $35-75 \%$ in 2015 using national District Health Information System (DHIS) 2 estimates), and high ART patient volume (> 120 patients enrolled in 2015 according to DHIS 2). Of the 27 eligible facilities, those that were primarily mental health facilities $(n=1)$, had related interventions in place $(n=1)$, or were located on islands $(n=4)$ were excluded, and of the 21 remaining facilities, 20 were randomly selected. All eligible facilities were level III or IV and all selected facilities agreed to participate. Level III and IV health facilities are primary health care facilities with general outpatient clinics and maternity wards. Level IV facilities also run operating theatres offering cesarean sections and minor surgeries.

\section{Description of the intervention}

The intervention included several components: 1) Training of expert clients (PLWHIV working at the facility as lay staff) in best practices for patient linkage/follow-up, including provision of flip charts with concrete guidance on best practices for patient follow-up and counseling and clearly defined roles and responsibilities; 2) Training and empowerment of facility or ART in-charges in best practices for supervision of patient linkage/follow-up, including provision of a trainer's manual on best practices for patient follow-up and counseling; 3) Training of district staff in enhanced supervision and oversight of patient follow-up at facilities through monitoring and stronger inter-facility communication, including provision of a trainer's manual on best practices for patient follow-up and counseling; 4) Financial and logistical support to facilities: facilities were provided with a cellular telephone and a small amount (approximately \$72 USD/month) of funding for phone follow-up and home visits. Tools were provided to enhance documentation of patient follow-up (use was optional and up to the discretion of facilities).

The training of health facility and/or ART clinic in-charges (approximately 2 senior level staff per facility) and district staff (approximately 1-2 per district) was a two-day training in Kampala (approximately 60 participants total) using didactic sessions with slides as well as small group discussions. This was considered a training of trainers: Participants were given a trainer's manual to be used at the facility trainings. The training of expert clients was a one-day training at each facility led by the ART in-charge, study staff, and where possible, a representative from the Ministry of Health, and expert clients were given flip charts as reference materials. The training materials were developed and adapted from a number of sources including an elimination of mother-to-child transmission training curriculum previously developed by the Uganda Ministry of Health, materials used in a small pilot led by the Uganda Ministry of Health and the Clinton Health Access Initiative in pediatric patients only, a flipchart for patient education developed by the World Health Organization (https://www.who.int/hiv/pub/imai/patient_flipchart/en/), and discussions with Ministry of Health, 
healthcare workers, and training experts. Best practices promoted in the trainings included improved tracking and documentation of patient appointments, contact information, and follow-up attempts, conducting up to two phone calls and two home visits to patients who missed appointments or did not link to care, and strengthened patient group education and individual counseling services to emphasize the importance of staying in care.

\section{Study design}

The intervention was evaluated using a pre-/post-intervention study design comparing patient outcomes before and after implementation, clustered by intervention facilities. Data from the 9 months prior to rollout of the intervention (December 25, 2015-September 25, 2016) was retrospectively collected in September-October 2016. The trainings were conducted in October-November 2016 and the intervention was considered to be in place as of November 14, 2016. Facility monitoring visits were conducted monthly for the first 3 months of intervention implementation and every other month for the following months to assess degree of implementation and troubleshoot any issues. Data from the 9 months after rollout of the intervention (November 14, 2016-August 14, 2017) was retrospectively collected in August 2017. Facility registers (HIV counseling and treatment register, daily lab testing log, early infant diagnosis (EID) register for polymerase chain reaction (PCR) testing, pre-ART register, ART register) and HIV patient care cards were examined to compare outcomes at baseline and endline. At baseline, we noted several pieces of information that were not part of the data collection plans in the original study protocol but that were available in the data sources and would be useful to better describe the study population: Entry point, history of HIV tests, TB status, and marital status for individuals testing positive for HIV and time since diagnosis, CD4 count and stage, and pregnancy/lactation status among individuals initiating treatment; therefore, we obtained approvals from the IRBs overseeing this study to collect this additional information at endline.

\section{Primary outcomes}

One of the primary study outcomes was linkage to care, defined as patients newly diagnosed with HIV who registered in pre-ART or ART care at the facility within 1 month of diagnosis. Adult patients who were diagnosed between December 25, 2015 and June 25, 2016 were sampled for inclusion in the pre-intervention period of the study and all pediatric patients diagnosed in that timeframe were included [21]. Due to budgetary constraints and for efficiency purposes given the large number of newly initiated patients, we did not collect data on all newly diagnosed patients but rather systematically sampled every xth patient on the testing register such that a minimum of 40 patients were sampled per facility and the smallest possible number of patients beyond that were sampled. For example, if there were 80 patients on the register, every other patient on the register was sampled. If the number of patients testing during the relevant time period was less than 60 patients, all patients were sampled for simplicity. Similarly, newly diagnosed adults were sampled and all newly diagnosed pediatric patients were included in the post-intervention period from November 14, 2016 and May 14, 2017. Newly diagnosed patients were followed for 3 months to assess linkage, and secondary analyses assessed linkage to care within 1 day, 1 week, or 3 months of HIV diagnosis.

The second primary study outcome was retention in care, defined as patients newly initiated on ART who had at least 1 visit to the health facility for ART care 3-6 months after initiation; this matches the Uganda Ministry of Health's definition of retention. Because the retention outcome required 6 months of follow-up out of the 9-month study periods, all patients who initiated ART at study facilities between December 25, 2015 and March 25, 2016 and were listed on the ART register were included in the pre-intervention retention assessment; patients initiating between November 14, 2016 and February 14, 2017 were included in the post-intervention retention assessment. Patient data were collected for the 6 months after ART initiation, and secondary analyses assessed the proportion of patients attending a first ART follow-up appointment, at least 4, 5, or 6 appointments over 6 months, mean number of appointments per patient, and adherence to appointment visit schedule (defined as coming to the facility within 1 week of the scheduled appointment). Patients missing the optimal data source for appointment dates (the patient care card) were excluded from the analysis on adherence to appointment schedule, as other data sources such as the ART register had less precision in reporting the appointment dates and often only reported appointment month.

\section{Data analysis}

Patient characteristics were assessed using proportions and medians/interquartile ranges (IQR). For the primary analyses comparing dichotomous linkage and retention outcomes before versus after implementation of the intervention, univariable logistic regression was performed. Linear regression was performed for continuous outcomes. Where univariable analyses were statistically significant or borderline significant, multivariable analyses were conducted adjusting for patient age group and sex. Facility-level clustering was accounted for in all individual-level regression analyses using the vce(cluster) function in Stata and the missing indicator method was used to account for missing covariate data.

Given that the intervention may have taken weeks to months to ramp up fully after the initial training, linkage and retention were examined by intervention month and 
sensitivity analyses were conducted in which the first month or months of the intervention were excluded from the analysis as a "ramp-up" period.

Analyses were conducted across all ages and stratified by age group. Facility-level characteristics were examined in relation to change in linkage by collapsing linkage and retention data to facility averages before versus after the intervention was implemented and performing linear regression with post-intervention linkage/retention as the outcome and facility characteristics such as size, staffing levels, and funding as the predictor variable, adjusting for pre-intervention linkage/retention. The study team also independently developed a facility leadership and participation score based on observations made at study monitoring visits. ART in-charge leadership and participation were each given a score of $0-2$ (with higher scores indicating better leadership and participation) and expert clients/facilitators were also given scores of $0-2$ in leadership and participation. These individual scores were summed for a combined maximum score of 8 and were assessed in relation to linkage and retention.

All analyses were completed in StataSE 13 (College Station, Texas).

\section{Costing}

Program costs were calculated, including the cost of the trainings, facility funding for phone airtime and home visits, and program supervision, and used to estimate the cost per additional patient linked to care and cost per additional patient retained in care by dividing the cost over a defined period to the number of additional patients linked to and retained in care over that timeframe using study outcome data.

\section{Results}

\section{Linkage to care}

The study sample to assess linkage to care initially included 1945 patients. 2 patients were excluded from the sample because they died over follow-up and 43 were excluded because they were reported as transferring to another facility over follow-up and this information could not be corroborated (these patients were included in the dataset in sensitivity analyses to ensure that findings were consistent). The final sample included 1900 patients newly diagnosed with HIV (928 pre-intervention, 972 post-intervention).

There were not substantial differences in demographic characteristics of patients in the pre-intervention sample versus post-intervention sample, although data on certain patient characteristics were collected post-intervention only (Table 1 ). Overall, $60.2 \%$ of patients were female. $7.2 \%$ of patients were age $<10$ years and $8.6 \%$ were $10-18$ years. Among patients $10-18$ years, sex demographics were more skewed: only $20.9 \%$ of those patients were male. While most patients (59.0\%) were missing
Table 1 Characteristics of 1900 patients testing HIV-positive preversus post-intervention at 20 facilities in Uganda ${ }^{a}$

\begin{tabular}{|c|c|c|c|c|}
\hline \multirow[t]{2}{*}{ Characteristic } & \multicolumn{2}{|c|}{ Pre-intervention } & \multicolumn{2}{|c|}{ Post-intervention } \\
\hline & $N$ & $\%$ & $N$ & $\%$ \\
\hline Total & 928 & & 972 & \\
\hline \multicolumn{5}{|l|}{ Sex } \\
\hline Female & 558 & $60.1 \%$ & 586 & $60.3 \%$ \\
\hline Male & 370 & $39.9 \%$ & 386 & $39.7 \%$ \\
\hline \multicolumn{5}{|l|}{ Age group } \\
\hline$<10$ years & 72 & $7.8 \%$ & 65 & $6.7 \%$ \\
\hline 10-18 years & 80 & $8.6 \%$ & 83 & $8.5 \%$ \\
\hline $19-48$ years & 683 & $73.6 \%$ & 729 & $75.0 \%$ \\
\hline $49+$ years & 71 & $7.7 \%$ & 59 & $6.1 \%$ \\
\hline Missing & 22 & $2.4 \%$ & 36 & $3.7 \%$ \\
\hline \multicolumn{5}{|l|}{ Clinical stage at diagnosis } \\
\hline I & 290 & $31.3 \%$ & 296 & $30.5 \%$ \\
\hline$\|$ & 90 & $9.7 \%$ & 56 & $5.8 \%$ \\
\hline III & 19 & $2.1 \%$ & 17 & $1.8 \%$ \\
\hline IV & 6 & $0.7 \%$ & 5 & $0.5 \%$ \\
\hline Missing & 523 & $56.4 \%$ & 598 & $61.5 \%$ \\
\hline \multicolumn{5}{|l|}{ Entry point } \\
\hline PMTCT & - & - & 69 & $7.1 \%$ \\
\hline Facility-based non-PMTCT & - & - & 782 & $80.5 \%$ \\
\hline Outreach & - & - & 98 & $10.1 \%$ \\
\hline Missing & - & - & 23 & $2.4 \%$ \\
\hline \multicolumn{5}{|l|}{ First HIV test } \\
\hline Yes & - & - & 372 & $38.3 \%$ \\
\hline No & - & - & 567 & $58.3 \%$ \\
\hline Missing & - & - & 33 & $3.4 \%$ \\
\hline \multicolumn{5}{|l|}{ Third HIV test or greater in last year } \\
\hline Yes & - & - & 418 & $43.0 \%$ \\
\hline No & - & - & 514 & $52.9 \%$ \\
\hline Missing & - & - & 40 & $4.1 \%$ \\
\hline \multicolumn{5}{|l|}{ TB status } \\
\hline Positive & & & 33 & $3.4 \%$ \\
\hline Negative or unknown & & & 939 & $96.6 \%$ \\
\hline \multicolumn{5}{|l|}{ Marital status } \\
\hline Married & - & - & 428 & $44.0 \%$ \\
\hline Never married & - & - & 269 & $27.7 \%$ \\
\hline Separated, divorced, or widowed & - & - & 104 & $10.7 \%$ \\
\hline Cohabitating & - & - & 32 & $3.3 \%$ \\
\hline Missing & - & - & 139 & $14.3 \%$ \\
\hline
\end{tabular}

${ }^{a} 2$ patients were excluded from the original sample because they died over follow-up; 43 were excluded because they were reported as transferring to another facility over follow-up and this information could not be corroborated. Data for certain indicators were only collected at endline 
information on clinical stage at diagnosis, few patients with known stage were stage III-IV (6.0\%). Among post-intervention patients, most $(80.5 \%)$ were identified through facility-based non-prevention of mother-to-child transmission (PMTCT) testing; 7.1\% came from PMTCT entry points and $10.1 \%$ came through patient outreach testing. $38.3 \%$ of patients were receiving their first HIV test, while $43.0 \%$ of patients were receiving their third HIV test or greater in the last year. $60.0 \%$ of the children $<10$ years and $55.4 \%$ of adolescents $10-18$ years were being tested for the first time. $3.4 \%$ of patients were known tuberculosis (TB) positive. There was a relatively high proportion of missing data on several demographic factors due to this information not being routinely documented at some facilities.

There were small increases in linkage to care after implementation of the intervention (Table 2; e.g. linkage to care within 1 month: $52.9 \%$ pre-intervention versus $54.9 \%$ post-intervention), but increases were not statistically significant regardless of the timeframe assessed (e.g. adjusted odds ratio, aOR for linkage within 1 month: 1.09, 95\% confidence interval, CI: $0.78-1.53 ; p=$ $0.63)$. Linkage to care did not change substantially over the intervention timeframe and there were not statistically significant increases in linkage in analyses stratified by sex or age group.

However, change in linkage to care after implementation of the intervention varied greatly by facility and several facility-level characteristics predicted greater increases in linkage to care. Overall, there was a greater increase in linkage among smaller facilities/programs: level III facilities (13.4\%) compared to level IV facilities (-1.6\%; effect estimate: $14.2,95 \%$ CI: $0.5-27.9 \% ; p=$ $0.04)$; facilities with fewer expert clients $(<5: 11.5 \%$; $5+$ : - 4.4\%; effect estimate: 14.3 , 95\% CI: 3.3-28.3\%; $p=$ $0.045)$; and facilities with fewer adult ART days per week ( 1 day: $16.7 \%$; $2+$ days: $-4.3 \%$; effect estimate: $17.4,95 \%$ CI: $3.9-30.9 \% ; p=0.01)$. There was also a greater increase in linkage among facilities reporting issues with phone funding at baseline (16.0\%) compared to those who did not report this as an issue $(-0.1 \%$; effect estimate: 15.8 , 95\% CI: $1.8-29.8 \%$; $p=0.03$ ).

\section{Retention in care}

Initially, 1442 patients who initiated on ART within the specified time frame were included in the study sample. However, 28 patients were excluded from the sample because they died over the 6 months of study follow-up and 58 were excluded because they were reported as transferring to another facility over follow-up and this information could not be corroborated (although these patients were included in the dataset in sensitivity analyses to ensure that findings were consistent). The final sample included 1356 patients newly initiated on ART (678 pre-intervention, 678 post-intervention).

Overall, $63.0 \%$ of patients newly initiated on ART were female; $4.2 \%$ were age less than 10 years and $4.1 \%$ were age $10-18$ years (Table 3 ). Again, among patients $10-18$ years, sex demographics were skewed: only $18.2 \%$ of those patients were male. Among patients from the post-intervention period, $39.4 \%$ initiated ART within 1 month of diagnosis and $6.3 \%$ initiated at least 1 year after diagnosis (note that Test and Treat policies were not implemented universally until 2017 in Uganda, when all patients became eligible for ART initiation regardless of CD4 T-cell count; however, some facilities with high-risk patients started Test and Treat prior to 2017). 5.1\% of patients were stage III or IV at initiation and $6.3 \%$ of patients were missing clinical stage at initiation, while $15.6 \%$ of patients had a CD4 count $<350$ cells $/ \mathrm{mcL}$ at initiation and $66.4 \%$ had missing CD4 information. Finally, $19.0 \%$ of patients were pregnant at initiation. There was a relatively high proportion of missing data on several demographic factors due to this information not being routinely documented at some facilities.

Patient appointment attendance appeared to increase after implementation of the intervention in univariable models as well as models adjusted for patient age and sex (Table 4). The percentage of patients coming to their first appointment increased from 85.3 to $90.3 \%$ (aOR: 1.61, 95\% CI: 1.05-2.47, $p=0.03$ ) and the percentage of patients coming to at least 4 appointments over 6 months of follow-up increased from 58.0 to $67.1 \%$ (aOR: 1.50, 95\% CI: $1.11-2.04, p=0.01$ ). Overall, the mean number of patient appointments increased after the

Table 2 Linkage to care among 1900 patients testing HIV-positive pre- versus post-intervention ${ }^{a}$

\begin{tabular}{|c|c|c|c|c|c|c|c|c|}
\hline \multirow[t]{2}{*}{ Outcome } & \multicolumn{2}{|c|}{ Pre-intervention } & \multicolumn{2}{|c|}{ Post-intervention } & \multirow[t]{2}{*}{ Univariable OR (95\% Cl) } & \multirow[t]{2}{*}{$p$} & \multirow{2}{*}{$\begin{array}{l}\text { Multivariable aOR } \\
(95 \% \mathrm{Cl})\end{array}$} & \multirow[t]{2}{*}{$p$} \\
\hline & N & $\%$ & $N$ & $\%$ & & & & \\
\hline Total & 928 & & 972 & & & & & \\
\hline Same day linkage to care & 271 & $29.2 \%$ & 303 & $31.2 \%$ & $1.10(0.81-1.50)$ & 0.59 & $1.09(0.80-1.49)$ & 0.57 \\
\hline Linkage to care within one week & 432 & $46.6 \%$ & 472 & $48.6 \%$ & $1.08(0.78-1.50)$ & 0.63 & $1.08(0.79-1.49)$ & 0.62 \\
\hline Linkage to care within 1 month & 491 & $52.9 \%$ & 534 & $54.9 \%$ & $1.09(0.77-1.54)$ & 0.65 & $1.09(0.78-1.53)$ & 0.63 \\
\hline Linkage to care within 3 months & 516 & $55.6 \%$ & 562 & $57.8 \%$ & $1.09(0.76-1.57)$ & 0.63 & $1.10(0.77-1.57)$ & 0.60 \\
\hline
\end{tabular}

Univariable and multivariable logistic regression accounting for facility-level clustering. Multivariable models adjust for patient age and sex 
Table 3 Characteristics of 1356 patients initiating antiretroviral therapy pre- versus post-intervention ${ }^{\mathrm{a}}$

\begin{tabular}{|c|c|c|c|c|}
\hline \multirow[t]{2}{*}{ Characteristic } & \multicolumn{2}{|c|}{ Pre-intervention } & \multicolumn{2}{|c|}{ Post-intervention } \\
\hline & $N$ & $\%$ & $N$ & $\%$ \\
\hline Total & 678 & & 678 & \\
\hline \multicolumn{5}{|l|}{ Sex } \\
\hline Female & 408 & $60.2 \%$ & 446 & $65.8 \%$ \\
\hline Male & 270 & $39.8 \%$ & 232 & $34.2 \%$ \\
\hline \multicolumn{5}{|l|}{ Age group } \\
\hline$<10$ years & 30 & $4.4 \%$ & 27 & $4.0 \%$ \\
\hline 10-18 years & 20 & $3.0 \%$ & 35 & $5.2 \%$ \\
\hline $19-48$ years & 542 & $79.9 \%$ & 558 & $82.3 \%$ \\
\hline $49+$ years & 64 & $9.4 \%$ & 54 & $8.0 \%$ \\
\hline Missing & 22 & $3.2 \%$ & 4 & $0.6 \%$ \\
\hline
\end{tabular}

Time from diagnosis to ART initiation

$\begin{array}{ll}<1 \text { month } & - \\ 1-<3 \text { months } & - \\ 3-<6 \text { months } & - \\ 6-<12 \text { months } & - \\ 12+\text { months } & - \\ \text { Missing } & -\end{array}$

$\begin{array}{lll}- & 267 & 39.4 \% \\ - & 49 & 7.2 \% \\ - & 28 & 4.1 \% \\ - & 26 & 3.8 \% \\ - & 43 & 6.3 \% \\ - & 265 & 39.1 \%\end{array}$

Clinical stage at initiation

$\begin{array}{lcccc}\text { I } & - & - & 432 & 63.7 \% \\ \text { II II } & - & - & 168 & 24.8 \% \\ \text { IV } & - & - & 30 & 4.4 \% \\ \text { Missing } & - & - & 5 & 0.7 \% \\ \text { CD4 count at initiation } & & - & 43 & 6.3 \% \\ <200 \text { cells/mcL } & - & - & 36 & 5.3 \% \\ \text { 200-<350 cells/mcL } & - & - & 70 & 10.3 \% \\ 350-<500 \text { cells/mcL } & - & - & 73 & 10.8 \% \\ \text { 500+ cells/mcL } & - & - & 49 & 7.2 \% \\ \text { Missing } & - & - & 450 & 66.4 \% \\ \text { Pregnancy/lactation status at initiation } & & & \\ \text { Pregnant } & - & - & 129 & 19.0 \% \\ \text { Lactating } & - & - & 15 & 2.2 \% \\ \text { None } & - & - & 534 & 78.8 \%\end{array}$

${ }^{a} 28$ patients were excluded from the original sample because they died over the 6 months of follow-up; 59 were excluded because they were reported as transferring to another facility over follow-up and this information could not be corroborated. Data for certain indicators were only collected at endline

intervention from 3.7 to 4.3 (effect estimate: 0.67, 95\% CI: $0.29-1.04, p=0.002)$ and more patients $(44.5 \%$ pre-intervention versus $55.2 \%$ post-intervention) adhered to their appointment schedule (aOR: 1.58, 1.132.22, $p=0.01$ ). In models using the full data set, the increase in $\mathrm{MOH}$-defined retention (coming to at least one appointment 3-6 months after ART initiation) was not statistically significant $(71.7 \%$ versus $75.7 \%$, aOR: 1.25, 95\% CI: 1.25, 95\% CI: 0.94-1.67, $p=0.12$ ). However, in sensitivity analyses, we noted that patient retention increased each month over the 3-month study enrollment period after the intervention was implemented. If the first month of intervention implementation was considered a "ramp-up" period and those data were excluded, the increase in retention before versus after the intervention became statistically significant $(71.7 \%$ versus $77.6 \%$, aOR: 1.41, 95\% CI: $1.08-1.84, p=0.01$ ).

The increases in patient adherence to appointment schedule and retention in care were more pronounced in pediatric and adolescent patients ages less than 19 years (Table 5). For example, adherence to appointment schedule increased from 33.3 to $60.9 \%$ in patients under 19 years (aOR: 3.31, 95\% CI: $1.41-7.79, \mathrm{p}=0.01$ ) and retention increased from 64.0 to $83.9 \%$ (aOR: 2.92 , 95\% CI: $1.31-6.51, \mathrm{p}=0.01)$.

Greater increases in retention were observed in facilities that demonstrated a stronger leadership and participation score (mean increase of $9.3 \%$ in facilities scoring 4-8 versus mean decrease of $5.5 \%$ at facilities with a score of < 4; effect estimate: 16.1, 95\% CI: $5.5-$ 26.7\%; $\mathrm{p}=0.01$ ).

The annual cost per additional patient retained in care was estimated to be $\$ 47$, dropping to $\$ 32$ if data from the one-month intervention ramp-up period were excluded.

\section{Discussions}

In this pre-/post-intervention study spanning 18 months, we observed a statistically significant increase in patient appointment attendance after implementation of a management intervention to promote improved patient follow-up and enhanced counseling. After excluding data from the intervention "ramp-up" period, there was a statistically significant increase in patient retention in care as well. Increases in patient retention and adherence to appointment schedule were most dramatic in pediatric and adolescent patients, who had a greater gap in retention at baseline compared to adults. Greater increases in retention in care were observed in facilities that demonstrated stronger leadership and participation in the intervention. We did not observe a significant increase in patient linkage to care, although there were greater improvements in patient linkage to care among smaller programs and in facilities reporting inadequate funding for phone follow-up at baseline.

Our study findings around improved retention after implementation of this intervention are in line with recent systematic reviews concluding that strategies such as task-shifting to peer health worker care as well as adherence support through counseling and education were effective in improving retention [15-17]. A recent study 
Table 4 Retention in care and adherence to appointment schedule among 1356 patients initiating antiretroviral therapy pre- versus post-intervention $^{a}$

\begin{tabular}{|c|c|c|c|c|c|c|c|c|}
\hline \multirow[t]{2}{*}{ Outcome } & \multicolumn{2}{|c|}{$\begin{array}{l}\text { Pre- } \\
\text { intervention }\end{array}$} & \multicolumn{2}{|c|}{$\begin{array}{l}\text { Post- } \\
\text { intervention }\end{array}$} & \multirow{2}{*}{$\begin{array}{l}\text { Univariable } \\
\text { OR/Effect } \\
\text { estimate } \\
(95 \% \mathrm{Cl})\end{array}$} & \multirow[t]{2}{*}{$p$} & \multirow{2}{*}{$\begin{array}{l}\text { Multivariable } \\
\text { aOR/Effect } \\
\text { estimate } \\
(95 \% \mathrm{Cl})\end{array}$} & \multirow[t]{2}{*}{$p$} \\
\hline & $N$ & $\begin{array}{l}\text { \%/Mean } \\
(\mathrm{SD})\end{array}$ & $N$ & $\begin{array}{l}\text { \%/Mean } \\
(\mathrm{SD})\end{array}$ & & & & \\
\hline Total & 678 & & 678 & & & & & \\
\hline Came to first appointment & 578 & $85.3 \%$ & 612 & $90.3 \%$ & $1.60(1.04-2.47)$ & 0.03 & $1.61(1.05-2.47)$ & 0.03 \\
\hline Came to at least 4 appointments & 393 & $58.0 \%$ & 455 & $67.1 \%$ & $1.48(1.10-1.99)$ & 0.01 & $1.50(1.11-2.04)$ & 0.01 \\
\hline Mean number of appointments & 678 & $3.7(2.2)$ & 678 & $4.3(2.4)$ & $0.65(0.28-1.02)$ & 0.002 & $0.67(0.29-1.04)$ & 0.002 \\
\hline Adhered to appointment schedule (within 1 week) & 236 & $44.5 \%$ & 295 & $55.2 \%$ & $1.54(1.10-2.15)$ & 0.01 & $1.58(1.13-2.22)$ & 0.01 \\
\hline $\begin{array}{l}\text { Came to an appointment } 3-6 \text { months after initiation ( } \mathrm{MOH} \text {-defined } \\
\text { retention) }\end{array}$ & 486 & $71.7 \%$ & 513 & $75.7 \%$ & $1.23(0.92-1.64)$ & 0.17 & $1.25(0.94-1.67)$ & 0.12 \\
\hline $\begin{array}{l}\text { Came to an appointment 3-6 months after initiation }(\mathrm{MOH} \text {-defined } \\
\text { retention), excluding first month of post-intervention enrollments }\end{array}$ & 486 & $71.7 \%$ & 347 & $77.6 \%$ & $1.37(1.06-1.78)$ & 0.02 & $1.41(1.08-1.84)$ & 0.01 \\
\hline
\end{tabular}

annivariable and multivariable logistic regression accounting for facility-level clustering. Multivariable models adjust for patient age and sex. Patients missing optimal data source for appointment dates (patient care card) were excluded from this analysis

among 5781 patients in Uganda, Kenya, and Tanzania reported that better patient tracing and follow-up procedures increased patient reengagement in care [22]. Our findings also complement a smaller study in Uganda with similar intervention components: After implementation of an appointment system, patient appointment books, and differentiated care for stable patients in 6 poorly-performing district hospitals, the proportion of missed appointments and medication gaps decreased; in this study, the reduction in medication gaps was greater in newly initiated patients [23]. A quasi-experimental study in 12 hospitals in Kenya also found that an

Table 5 Retention in care and adherence to appointment schedule pre- versus post-intervention stratified by age group ${ }^{a}$

\begin{tabular}{|c|c|c|c|c|c|c|}
\hline \multirow[t]{2}{*}{ Outcome } & \multicolumn{2}{|c|}{ Pre-intervention } & \multicolumn{2}{|c|}{ Post-intervention } & \multirow{2}{*}{$\begin{array}{l}\text { aOR/Effect estimate } \\
(95 \% \mathrm{Cl})\end{array}$} & \multirow[t]{2}{*}{$p$} \\
\hline & N & $\%$ & N & $\%$ & & \\
\hline$<10$ years & 30 & & 27 & & & \\
\hline Came to at least 4 appointments & 17 & $56.7 \%$ & 21 & $77.8 \%$ & $2.65(0.74-9.53)$ & 0.14 \\
\hline Adhered to appointment schedule & 9 & $36.0 \%$ & 17 & $85.0 \%$ & $12.39(3.64-42.19)$ & $<0.001$ \\
\hline MOH-defined retention & 22 & $73.3 \%$ & 25 & $92.6 \%$ & $4.36(0.94-20.20)$ & 0.06 \\
\hline 10-18 years & 20 & & 35 & & & \\
\hline Came to at least 4 appointments & 11 & $55.0 \%$ & 23 & $65.7 \%$ & $1.41(0.49-4.04)$ & 0.52 \\
\hline Adhered to appointment schedule & 4 & $28.6 \%$ & 11 & $42.3 \%$ & $2.01(0.52-7.71)$ & 0.31 \\
\hline $\mathrm{MOH}$-defined retention & 10 & $50.0 \%$ & 27 & $77.1 \%$ & $3.43(1.19-9.83)$ & 0.02 \\
\hline $19+$ years & 606 & & 612 & & & \\
\hline Came to at least 4 appointments & 353 & $58.3 \%$ & 408 & $66.7 \%$ & $1.44(1.05-1.97)$ & 0.02 \\
\hline Adhered to appointment schedule & 218 & $45.7 \%$ & 265 & $54.8 \%$ & $1.46(1.03-2.06)$ & 0.03 \\
\hline MOH-defined retention & 440 & $72.6 \%$ & 458 & $74.8 \%$ & $1.14(0.84-1.56)$ & 0.40 \\
\hline$<19$ years & 50 & & 62 & & & \\
\hline Came to at least 4 appointments & 28 & $56.0 \%$ & 44 & $71.0 \%$ & $1.95(0.83-4.59)$ & 0.13 \\
\hline Adhered to appointment schedule & 13 & $33.3 \%$ & 28 & $60.9 \%$ & $3.31(1.41-7.79)$ & 0.01 \\
\hline MOH-defined retention & 32 & $64.0 \%$ & 52 & $83.9 \%$ & $2.92(1.31-6.51)$ & 0.01 \\
\hline
\end{tabular}

${ }^{a}$ Sex-adjusted logistic regression accounting for facility-level clustering 
intervention involving better appointment tracking at the facility and more supervision led to better patient appointment attendance [24].

We observed a greater increase in retention among pediatric and adolescent patients, although this subgroup was small. Pediatric and adolescent patients tend to have lower retention compared to adults, so this represents a high-risk group that may need additional support. A recent systematic review on strategies to increase linkage and retention noted that there is a paucity of data on effective interventions for adolescents [17], and the findings from this study provide much-needed evidence on interventions that may be effective in this age group. Our findings support the implementation of this relatively low-cost and scalable intervention to real-world settings struggling with retention.

The lack of a significant improvement in linkage overall may be explained by a number of factors. First, there were a high proportion of migratory patients at many of the study facilities, with no contact information or fixed address for follow-up. When these patients tested positive, facility staff had no means to reach them again if they did not immediately enroll in care. Second, the laboratory staff conducting HIV testing did not necessarily attend the intervention training, and testing services exist across many entry points within facilities (such as antenatal care, voluntary counseling and testing, and outreach), and patient information for those who tested positive at times was not collected or did not make it to the ART clinic for staff to track and follow-up. Based on this, we recommend that HIV testing registers are updated to include space for detailed patient contact information and that trainings on patient follow-up include all staff involved in patient testing, treatment, documentation, follow-up, and counseling to ensure that everyone works together to improve the process. With better implementation of these practices, it may be possible to improve linkage to care in certain settings. For example, in a randomized trial in Uganda, an extended counseling program involving a post-test visit and monthly 2-hour home visits nearly doubled linkage to care $(67.5 \%$ versus $38.5 \%)$ [25].

This study had several limitations. Given the pre-/poststudy design, we were unable to account for temporal changes in the study outcomes due to policy changes or other factors. The analysis relies on retrospective collection of data using health records that in some cases may have been incomplete/incorrect. We were unable to confirm outcomes of patients who were lost to follow-up; some of these patients may have transferred to another facility for care or died. The accuracy and completeness of the registers may have improved because of the intervention, affecting the comparisons; however, no substantive changes occurred in the register system after the intervention. Study results may not be generalizable to sites with much higher baseline retention values and the impact of the intervention may be attenuated in these settings. Finally, we did not assess the sustainability of the intervention over a longer time period.

Strengths of this study include the relatively large number of facilities and large number of patients (>3000), which both demonstrate a wide variety of characteristics; the inclusion of pediatric and adolescent patients, which are priority groups due to higher risk of attrition at these ages; and the comprehensive data collection and analysis accounting for patient- and facility-level characteristics and including qualitative feedback from facility staff and patients.

\section{Conclusion}

Given the success of this intervention in improving patient retention in care, particularly for pediatric and adolescent patients, and its relatively low cost, this approach should be considered for scale-up in similar settings in Uganda and elsewhere. A recent analysis noted that interventions to improve linkage and retention in care were likely to be more cost-effective than increasing HIV testing rates [26]; these types of relatively low-cost interventions should be emphasized as a strategy to reduce the burden of HIV.

\section{Abbreviations}

ART: Antiretroviral therapy; aOR: Adjusted odds ratio; DHIS: District Health Information System; EID: Early infant diagnosis; IQR: Interquartile range; PCR: Polymerase chain reaction; PLWHIV: People living with HIV; PMTCT: Nonprevention of mother-to-child transmission; TB: Tuberculosis

\section{Acknowledgements}

The authors acknowledge the Uganda Ministry of Health for their support of this work, the healthcare workers at study facilities, and the study data collectors

\section{Funding}

Funding was provided through the UK Department for International Development (DFID) grant 202575-105. DFID did not play a role in the study design, data collection, analysis, interpretation of data, or writing the manuscript.

\section{Availability of data and materials}

Datasets used and/or analysed for this study are available from the corresponding author on reasonable request.

\section{Authors' contributions \\ The study was conceived of and designed by CB, KG, EM, PN, VM, VB, PM, $A M$, and CK. VN and AR led study implementation and data collection. Data analysis was conducted by CB. CB wrote the initial draft of the manuscript. All authors critically interpreted study findings and read and approved the final manuscript.}

\section{Ethics approval and consent to participate}

Ethics approvals were granted by Makerere University School of Health Sciences Research and Ethics Committee (protocol \#2016-032), the Uganda National Council for Science and Technology (\#HS 2106), and Chesapeake IRB (\#Pro00018902). The IRBs overseeing this work waived the need for informed consent for the facility-based retrospective data collection. 


\section{Competing interests}

The authors declare that they have no competing interests.

\section{Publisher's Note}

Springer Nature remains neutral with regard to jurisdictional claims in published maps and institutional affiliations.

\section{Author details}

${ }^{1}$ Clinton Health Access Initiative (CHAl), 383 Dorchester Road, Suite 400, Boston, MA 02127, USA. ${ }^{2} \mathrm{CHAl}$, Kampala, Uganda. ${ }^{3}$ Ministry of Health, Kampala, Uganda.

Received: 24 May 2018 Accepted: 19 November 2018

Published online: 06 December 2018

\section{References}

1. Uganda MoH. Q3. Uganda ART quarterly report. In: 2014; 2014.

2. USAID. Strengthening Uganda's Systems for Treating AIDS nationally (SUSTAIN). Quarterly Report January 1-March. 2015:31.

3. Koole O, Tsui S, Wabwire-Mangen F, Kwesigabo G, Menten J, Mulenga M, et al. Retention and risk factors for attrition among adults in antiretroviral treatment programmes in Tanzania. Uganda and Zambia Trop Med Int Health. 2014;19: 1397-410.

4. Mugasha C, Kigozi J, Kiragga A, Muganzi A, Sewankambo N, Coutinho A, et al. Intra-facility linkage of HIV-positive mothers and HIV-exposed babies into HIV chronic care: rural and urban experience in a resource limited setting. PLoS One. 2014:9:e115171.

5. Granich R, Gupta S, Hall I, Aberle-Grasse J, Hader S, Mermin J. Status and methodology of publicly available national HIV care continua and 90-90-90 targets: a systematic review. PLoS Med. 2017;14:e1002253.

6. Geng EH, Odeny TA, Lyamuya R, Nakiwogga-Muwanga A, Diero L, Bwana M, et al. Retention in care and patient-reported reasons for undocumented transfer or stopping care among HIV-infected patients on antiretrovira therapy in eastern Africa. Application of a sampling-based approach. Clin Infect Dis. 2016;62:935-44.

7. Namusobya J, Semitala FC, Amanyire G, Kabami J, Chamie G, Bogere J, et al. High retention in care among HIV-infected patients entering care with CD4 levels $>350$ cells/muL under routine program conditions in Uganda. Clin Infect Dis. 2013;57:1343-50.

8. Okoboi S, Ding E, Persuad S, Wangisi J, Birungi J, Shurgold S, et al. Community-based ART distribution system can effectively facilitate longterm program retention and low-rates of death and virologic failure in rural Uganda. AIDS Res Ther. 2015:12:37.

9. Brown LB, Havlir DV, Ayieko J, Mwangwa F, Owaraganise A, Kwarisiima D, et al. High levels of retention in care with streamlined care and universal test and treat in East Africa. AIDS. 2016;30:2855-64.

10. Bulsara SM, Wainberg ML, Newton-John TR. Predictors of adult retention in HIV care: a systematic review. AIDS Behav. 2018;22:752-64.

11. Nabukeera-Barungi N, Elyanu P, Asire B, Katureebe C, Lukabwe I, Namusoke E, et al. Adherence to antiretroviral therapy and retention in care for adolescents living with HIV from 10 districts in Uganda. BMC Infect Dis. 2015;15:520.

12. Fox MP, Rosen S, Geldsetzer P, Barnighausen T, Negussie E, Beanland R. Interventions to improve the rate or timing of initiation of antiretroviral therapy for HIV in sub-Saharan Africa: meta-analyses of effectiveness. J Int AIDS Soc. 2016;19:20888

13. Keane J, Pharr JR, Buttner MP, Ezeanolue EE. Interventions to reduce loss to follow-up during all stages of the HIV care continuum in sub-Saharan Africa: a systematic review. AIDS Behav. 2017:21:1745-54.

14. Govindasamy D, Meghij J, Kebede Negussi E, Clare Baggaley R, Ford N, Kranzer K. Interventions to improve or facilitate linkage to or retention in pre-ART (HIV) care and initiation of ART in low- and middle-income settings--a systematic review. J Int AIDS Soc. 2014;17:19032.

15. Vrazo AC, Firth J, Amzel A, Sedillo R, Ryan J, Phelps BR. Interventions to significantly improve service uptake and retention of HIV-positive pregnant women and HIV-exposed infants along the prevention of mother-to-child transmission continuum of care: systematic review. Tropical Med Int Health. 2018:23:136-48

16. Scanlon ML, Vreeman RC. Current strategies for improving access and adherence to antiretroviral therapies in resource-limited settings. HIV AIDS (Auckl). 2013;5:1-17.
17. Murray KR, Dulli LS, Ridgeway K, Dal Santo L, Darrow de Mora D, Olsen P, et al. Improving retention in HIV care among adolescents and adults in low- and middle-income countries: a systematic review of the literature. PLoS One. 2017;12:e0184879.

18. Mutasa-Apollo T, Ford N, Wiens M, Socias ME, Negussie E, Wu P, et al. Effect of frequency of clinic visits and medication pick-up on antiretroviral treatment outcomes: a systematic literature review and meta-analysis. J Int AIDS Soc. 2017;20:21647.

19. Agwu AL, Fairlie L. Antiretroviral treatment, management challenges and outcomes in perinatally HIV-infected adolescents. J Int AIDS Soc. 2013;16:18579.

20. Abuogi LL, Smith C, McFarland EJ. Retention of HIV-infected children in the first 12 months of anti-retroviral therapy and predictors of attrition in resource limited settings: a systematic review. PLoS One. 2016:11:e0156506.

21. Boeke CE, Nabitaka V, Rowan A, Guerra K, Kabbale A, Asire B, et al. Assessing linkage to and retention in care among HIV patients in Uganda and identifying opportunities for health systems strengthening: a descriptive study. BMC Infect Dis. 2018;18:138.

22. Bershetyn A, Odeny TA, Lyamuya R, Nakiwogga-Muwanga A, Diero L, Bwana $M$, et al. The causal effect of tracing by peer health workers on return to clinic among patients who were lost to follow-up from antiretroviral therapy in eastern Africa: a "natural experiment" arising from surveillance of lost patients. Clin Infect Dis. 2017:64:1547-54.

23. Obua C, Kayiwa J, Waako P, Tomson G, Balidawa H, Chalker J, et al. Improving adherence to antiretroviral treatment in Uganda with a lowresource facility-based intervention. Glob Health Action. 2014;7:24198.

24. Boruett P, Kagai D, Njogo S, Nguhiu P, Awuor C, Gitau L, et al. Facility-level intervention to improve attendance and adherence among patients on anti-retroviral treatment in Kenya--a quasi-experimental study using time series analysis. BMC Health Serv Res. 2013;13:242

25. Muhamadi L, Tumwesigye NM, Kadobera D, Marrone G, Wabwire-Mangen F, Pariyo $\mathrm{G}$, et al. A single-blind randomized controlled trial to evaluate the effect of extended counseling on uptake of pre-antiretroviral care in eastern Uganda. Trials. 2011:12:184.

26. McCreesh N, Andrianakis I, Nsubuga RN, Strong M, Vernon I, McKinley TJ, et al. Universal test, treat, and keep: improving ART retention is key in cost-effective HIV control in Uganda. BMC Infect Dis. 2017;17:322.

Ready to submit your research? Choose BMC and benefit from:

- fast, convenient online submission

- thorough peer review by experienced researchers in your field

- rapid publication on acceptance

- support for research data, including large and complex data types

- gold Open Access which fosters wider collaboration and increased citations

- maximum visibility for your research: over $100 \mathrm{M}$ website views per year

At BMC, research is always in progress.

Learn more biomedcentral.com/submissions 